\title{
Mib2 Deficiency Inhibits Microglial Activation and Alleviates Ischemia-Induced Brain Injury
}

\author{
Xiaoheng Li ${ }^{1}$, Yajin Liao ${ }^{2,3}$, Yuan Dong ${ }^{4}$, Shuoshuo Li ${ }^{5}$, Fengchao Wang ${ }^{6}$, Rong Wu², Zengqiang \\ Yuan ${ }^{1,2 *}$, Jinbo Cheng ${ }^{2,3 *}$
}

${ }^{1}$ Beijing Institute for Brain Disorders, Capital Medical University, Beijing, China. ${ }^{2}$ The Brain Science Center, Beijing Institute of Basic Medical Sciences, Beijing, China. ${ }^{3}$ Center on Translational Neuroscience, College of Life \& Environmental Science, Minzu University of China, Beijing, China . ${ }^{4}$ Department of Biochemistry, Medical College, Qingdao University, Qingdao, Shandong, China. ${ }^{5}$ The State Key Laboratory of Brain and Cognitive Sciences, Institute of Biophysics, Chinese Academy of Sciences, Beijing, China. ${ }^{6}$ National Institute of Biological Sciences, Beijing, China.

[Received April 12, 2019; Revised August 6, 2019; Accepted August 7, 2019]

\begin{abstract}
Neuroinflammation plays a critical role in ischemia-induced brain injury. Mib2, an E3 ubiquitin ligase, has been reported to regulate Notch signaling and participate in the peripheral immune system. However, the roles of Mib2 in the nervous system are not well characterized. In this study, we show that Mib2 is involved in lipopolysaccharide (LPS)- and oxygen-glucose deprivation (OGD)-induced microglial activation. Mechanistically, Mib2 interacts with the IKK complex and regulates the activation of NF-KB signaling, thus modulating Notch1 transcription in the microglia. Furthermore, we generated a microglia-specific Mib2 knockout mice and found that microglia-specific deletion of Mib2 significantly alleviates ischemia-induced neuroinflammation and brain injury. Taken together, our results reveal a critical role of Mib2 in microglial activation and ischemia-induced brain injury, thus providing a potential target for the treatment of stroke.
\end{abstract}

Key words: Mib2, microglia, neuroinflammation, ischemia, brain injury

Neuroinflammation, generally regarded as a detrimental factor for neurological functions, is involved in various central nervous system (CNS) diseases. It can be triggered by a variety of stimuli including microbes, brain injury, toxic metabolites, autoimmune response, and neurodegeneration [1-3]. Emerging evidence showed that neuroinflammation is tightly linked to the pathophysiology of stroke, which is the second-largest cause of death worldwide [4, 5]. During stroke, ischemia and hypoxia trigger a robust immune response and the inflammation is maintained throughout the period, from early damage to post-stroke tissue repair [4-6].
As the resident immune cell, microglia are highly ramified and motile and serve as the guardian of the CNS $[2,7]$. Each microglial cell possesses its territory and constantly surveys the local microenvironment through its delicate processes $[7,8]$. Upon ischemia, microglial cells, which are the first activated cells in the brain parenchyma, migrate to the infarction area and produce proinflammatory cytokines to initiate an immune response, thus play a critical role in stroke $[9,10]$. In addition, microglial cells undergo a morphology change, from ramified to amoeboid state under which the cells display round soma and no processes [11]. Recent studies have

*Correspondence should be addressed to: Drs. Jinbo Cheng (Email: cheng_jinbo@126.com) and Zengqiang Yuan (Email: zqyuan@bmi.ac.cn), The Brain Science Center, Beijing Institute of Basic Medical Sciences, Beijing, China.

Copyright: (C) $2019 \mathrm{Li} \mathrm{X}$ et al. This is an open-access article distributed under the terms of the Creative Commons Attribution License, which permits unrestricted use, distribution, and reproduction in any medium, provided the original author and source are credited. 
shown that NF- $\kappa \mathrm{B}-$ and Notch-signaling contribute towards the activation of microglia after stroke [12-14]. However, the precise mechanism of microglial activation in this process is not well understood.

Mind bomb-2 (Mib2) is an E3 ubiquitin ligase, which operates in conjunction with E1 ubiquitin-activating enzyme and E2 ubiquitin-conjugating enzyme, and ubiquitinates specific proteins [15]. It has been reported that Mib2 could ubiquitinate the Notch ligand to regulate the Notch signaling [16, 17]. Mib2 also participates in the regulation of NF- $\kappa \mathrm{B}$ signaling and type I interferon responses $[18,19]$. Mib2 knockout mice displayed defects in the hippocampal spatial memory and contextual fear memory [20], indicating that Mib2 plays a role in the brain functions. Furthermore, the N-methyl-D-aspartate receptor NR2B subunit [21] and GABAB receptors [22, 23] have been reported as Mib2 substrates. Intriguingly, Mib2 is highly expressed in microglia [24], however, its function in microglia remains to be elucidated.

Here, we demonstrate that Mib2 promotes microglial activation by regulating NF- $\mathrm{KB}$ and Notch1 signaling pathways. Furthermore, microglia specific deletion of Mib2 reduces its activation and neuroinflammation as well as brain damage after ischemic stroke, implicating that Mib2 might be a potential therapeutic target in stroke treatment.

\section{MATERIALS AND METHODS}

\section{Reagents and antibodies}

The following reagents were purchased: lipopolysaccharide (LPS; Sigma-Aldrich, St. Louis, MO, USA), Tamoxifen (\#S1238, Selleckchem, Houston, TX, USA). Antibodies used for immunoblotting were as follows: anti-Mib2 (\#118K4777, Sigma-Aldrich), anti-iNOS/NOS Type II (\#610332, BD Biosciences, San Jose, CA, USA), anti-Phospho-IKK $\alpha / \beta$ (S176/180) (16A6) (\#2697P), Notch1(D1E11) (\#3608S), anti-p44/42 MAPK (Erk1/2) (\#9102), anti-Phospho-p44/42 MAPK (Erk1/2) (Thr202/ Tyr204) (\#9101) were purchased from Cell Signaling Technology (Beverly, MA, USA), anti-IKK $\alpha$ (CHUK) (\#A2062), anti-IKK $\beta$ (\#A2087) were from ABclonal Technology (Wuhan, HB, China), anti-mouse/human CD11b (\#101217), anti-mouse CD45 (\#103110) were purchased from BioLegend (San Diego, CA, USA), antiMyc (\#M047-3), anti-HA (\#M180-3) were from MBL (Woburn, MA, USA), anti-Flag (\#F3165, SigmaAldrich), anti- $\beta$-tubulin (\#CW0098A) and anti-GAPDH (\#CW0266A) were from CWBiotech (Beijing, China), anti- $\beta$-actin (60008-1-Ig, Proteintech Group, Campbell Park, Chicago, IL, USA).

Aging and Disease • Volume 11, Number 3, June 2020

\section{Mice}

Mib2 conditional knockout mice were generated using the CRISPR/Cas 9 technology. Briefly, loxP elements were inserted upstream and downstream of exon 5 of Mib2, and $M i b 2^{f l o x /+}$ mice were confirmed by Southern blot. To generate microglia-specific and inducible knockout mice, homozygous Mib2 $2^{\text {flox fllox }}$ mice were crossed with the mice expressing tamoxifen (TAM)-inducible Cre-recombinase under the control of the $\mathrm{Cx} 3 \mathrm{cr} 1$ promoter $\left(\mathrm{Cx} 3 \mathrm{crl} 1^{\mathrm{CreER}}\right.$ mice) [25]. Mice were given TAM by intragastric administration at the age of P30 to induce microglial specific knockout. All mice were housed under a $12 \mathrm{~h} / 12$ $\mathrm{h}$ light-dark cycle at $22-24{ }^{\circ} \mathrm{C}$ with free access to water. All the animal experimental procedures were reviewed and approved by the Institutional Animal Care and Use Committee of the Beijing Institute of Basic Medical Sciences (Beijing, China).

\section{Cell culture and transfection}

HEK 293 T and BV2 cell lines were obtained from ATCC (Manassas, VA, USA) and maintained in Dulbecco's modified Eagle's medium (DMEM, Invitrogen, Waltham, MA, USA) supplemented with $10 \%$ fetal bovine serum (FBS, Gibco, Grand Island, NY, USA) and 1\% PenicillinStreptomycin (Invitrogen). All cells were maintained in a $5 \% \mathrm{CO}_{2}$ atmosphere at $37{ }^{\circ} \mathrm{C}$.

Transient knockdown in BV2 cells was performed by siRNA transfection with Lipofectamine ${ }^{\circledR}$ RNAiMAX Transfection Reagent (\#13778150, Invitrogen). The targeting sequences of siRNAs were: Mib2 1\#: CUCUA UGACAACGCCCAAATT; Mib2 2\#: CGCUAUGAGA CAUCUCACUTT; Notch: CCUUUCUACCGCUGUCU AUTT.

For stable knockdown in BV2 cells, shRNA against Mib2 (targeting sequence: TCGAAGGATGAAGAAGT GTAT) was used. Briefly, the complementary sequences of shRNA were annealed together and ligated into a pLKO.1 lentiviral vector (Addgene, Cambridge, MA, USA) and then co-transfected with viral packaging plasmids (VSVG and $\triangle$ R812) into HEK 293T cells. After transfection, the viral supernatant was collected (once a day for two days), centrifuged, and filtered through a 0.45 $\mu \mathrm{m}$ filter. The supernatant was used to infect the BV2 cells with polybrene (\#sc-134220, Santa Cruz Biotechnology, 1:1000). Three days after the infection, cells were subjected to antibiotic selection.

\section{Immunoprecipitation and immunoblotting}

Western blot analyses were conducted as previously described [26, 27]. For immunoprecipitation, 293T cells were lysed on ice using immunoprecipitation lysis buffer 
(50 mM Tris- $\mathrm{HCl}$ (pH 7.4), $150 \mathrm{mM} \mathrm{NaCl}, 1 \mathrm{mM}$ EDTA, $1 \mathrm{mM}$ EGTA, $5 \mathrm{mM}$ Na4Ppi, $25 \mathrm{mM} \mathrm{NaF}, 1 \%$ Triton $\mathrm{X}$ 100, $1 \mathrm{mM}$ PMSF, and protease inhibitor cocktail) for 20 $\mathrm{min}$, followed by centrifugation at $13000 \mathrm{rpm}$ for $15 \mathrm{~min}$. The supernatant was pre-cleared with protein $\mathrm{G}$ agarose beads followed by immunoprecipitation at $4{ }^{\circ} \mathrm{C}$ for $2 \mathrm{~h}$ using $\operatorname{IgG}$ or specific antibody-conjugated beads. The immunoprecipitates were washed five times with the immunoprecipitation wash buffer $(50 \mathrm{mM}$ Tris- $\mathrm{HCl}(\mathrm{pH}$ 7.4), $150 \mathrm{mM} \mathrm{NaCl}, 1 \mathrm{mM}$ EDTA, $1 \mathrm{mM}$ EGTA, $5 \mathrm{mM}$ Na4Ppi, $25 \mathrm{mM} \mathrm{NaF}, 0.5 \%$ Triton X-100) and centrifuged at $3000 \mathrm{rpm}$ for $3 \mathrm{~min}$ each time. The immunoprecipitated proteins were eluted using SDS-PAGE loading buffer and analyzed by western blot.

\section{The IKK complex ubiquitylation assays}

The ubiquitination assays were performed as previously described [28]. The cells were lysed on ice in lysis buffer (50 mM Hepes ( $\mathrm{pH} 7.4$ ), $150 \mathrm{mM} \mathrm{NaCl}, 1 \%$ Nonidet P$40,0.1 \%$ deoxycholate, $0.05 \%$ SDS, $0.1 \mathrm{M} \mathrm{NaF}, 1 \mathrm{mM}$ EGTA and protease inhibitor cocktail) for $20 \mathrm{~min}$, followed by centrifugation at $14000 \mathrm{rpm}$ for $15 \mathrm{~min}$. The supernatant was pre-cleared and then incubated with Myc antibody-conjugated beads for $3 \mathrm{~h}$. Then the beads were washed 4 times using lysis buffer, and the proteins were eluted using SDS-PAGE loading buffer and analyzed by western blot.

\section{Dual-luciferase reporter system}

Mouse NF- $\kappa \mathrm{B}$ and Hes1 reporters were generated in our laboratory. Notch1 promoter ( $-2000 \mathrm{bp}$ to $+550 \mathrm{bp}$ ) was cloned into a pGL3-luciferase reporter vector (Promega, Madison, WI, USA). The control pCMV-Renilla plasmid and the other plasmids were co-transfected into 293T cells. $16 \mathrm{~h}$ after transfection, the cells were lysed, and the luciferase activity was measured.

\section{Isolation of murine microglia and flow cytometry analysis}

Microglia were isolated by Percoll density gradient purification [29, 30]. In brief, fresh brain tissue was rinsed twice with PBS with $2 \%$ FBS, disrupted mechanically and then enzymatically digested using type IV collagenase (\#17104019, Gibco) for $15 \mathrm{~min}$ at $37^{\circ} \mathrm{C}$. The suspension was filtered through a $70 \mu \mathrm{m}$ filter and centrifuged at 600 $\mathrm{g}$ for $6 \mathrm{~min}$ at $4{ }^{\circ} \mathrm{C}$. The pellet was resuspended in $37 \%$ Percoll (diluted by PBS) and added to a graduated Percoll (\#17-0891-01, GE Healthcare, Uppsala, Sweden) gradient prepared in a $15 \mathrm{~mL}$ conical bottomed tube followed by centrifugation at $2000 \mathrm{~g}$ for $20 \mathrm{~min}$ at $4{ }^{\circ} \mathrm{C}$. The cell layer was collected and rinsed with PBS and centrifuged at 600 g for 6 min at $4{ }^{\circ} \mathrm{C}$. After centrifugation, the supernatant was discarded, and the cells were resuspended in PBS (with 2\% FBS) and stained with anti-CD11b-FITC and anti-CD45-Cy5 (Biolegend) antibodies at concentrations recommended by the manufacturer and incubated at room temperature in dark for $30 \mathrm{~min}$. The stained cells were analyzed and sorted on the FACS Vantage (BD Biosciences) flow cytometer. The sorted microglial cells were collected by centrifugation and lysed using TRIzol $^{\text {TM }}$ Reagent (\#15596018, Invitrogen) for RNA isolation and subsequent RT-qPCR.

\section{RNA isolation and RT-qPCR}

Tissues, cultured cells, and sorted cells were lysed in TRIzol $^{\mathrm{TM}}$ Reagent. Tissues were finely chopped in TRIzol and immediately homogenized using a homogenizer. Total RNA was isolated according to the manufacturer's instructions. mRNA was converted to cDNA using the cDNA synthesis kit (AE311-03, TransGen Biotech, Beijing, China). RT-qPCR was performed with the diluted cDNA in three wells for each primer using SYBR green master mix (Bio-Rad) on a Bio-Rad iCycler iQ Real Time PCR system. All RT-qPCR experiments were repeated at least three times. The primers for RT-qPCR are shown in Supplementary Table 1.

\section{Immunofluorescence}

Tissues were formalin-fixed, paraffin-embedded, and sectioned. After de-paraffinization and rehydration, antigen retrieval was performed in citrate buffer ( $\mathrm{pH}$ 6.0) for $20 \mathrm{~min}$ at $95-100{ }^{\circ} \mathrm{C}$. The slides were then treated with $10 \%$ normal horse serum for $1 \mathrm{~h}$ at room temperature followed by incubation with anti-Iba1 antibody (1:400 at $4{ }^{\circ} \mathrm{C}$ overnight, Wako, 019-19741, Chuo-Ku, Osaka, Japan). The slides were then washed and incubated with the fluorescence conjugated secondary antibody in dark for $1 \mathrm{~h}$ at room temperature. After, the sections were rinsed and incubated with DAPI (Invitrogen) and visualized by immunofluorescent microscopy. The staining of all the slides was blinded. The number of Iba1 positive cells and soma area were analyzed at $20 \times$ magnification using Image $\mathbf{J}$ software (NIH, Bethesda, MD, USA).

\section{TTC Staining}

After $24 \mathrm{~h}$ or $72 \mathrm{~h}$ of reperfusion, mice were anesthetized and the brain was perfused using saline. After, the brain was cut into eight $1 \mathrm{~mm}$ serial coronal sections and incubated in $1.5 \%$ 2,3,5-triphenyltetrazolium chloride (TTC; $v / v$ in saline, Sigma-Aldrich) solution for $5 \mathrm{~min}$ at $37{ }^{\circ} \mathrm{C}$ as previously described [31-33]. Images were 
obtained and the infarct volumes were analyzed using ImageJ software. The final infarct volumes were presented as a ratio of the volume of ischemic tissue area to the total volume in all serial coronal sections.

\section{tMCAo model}

For focal cerebral ischemia, we induced right-side transient tMCAo as described previously [33]. For reperfusion, we removed the monofilament from the MCA and the suture occluding CCA (common carotid artery) $75 \mathrm{~min}$ after the occlusion.

\section{OGD model}

For oxygen-glucose deprivation, cells were rinsed and incubated in glucose-free Minimum Essential Medium (MEM; Gibco) and then transferred to an anaerobic chamber containing a mixture of $95 \% \mathrm{~N} 2$, and $5 \% \mathrm{CO}_{2}$ and incubated at $37^{\circ} \mathrm{C}$ for $3 \mathrm{~h}$. Cells were then switched to the normal culture medium and culture conditions to terminate the OGD treatment.

\section{Statistical analysis}

The results are shown as mean \pm SEM. Statistical analysis was performed using ImageJ software and GraphPad Prism 6 (GraphPad Software, San Diego, CA, USA). Ttest was used to compare two groups and one-way ANOVA for multiple groups. $p<0.05$ was considered statistically significant.
A

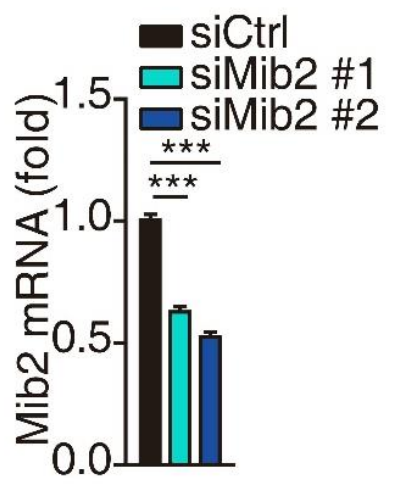

B

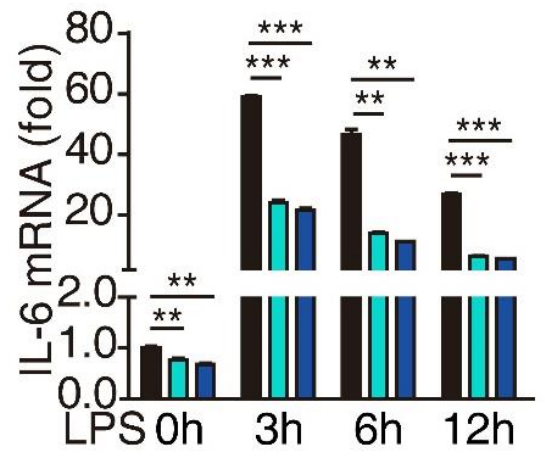

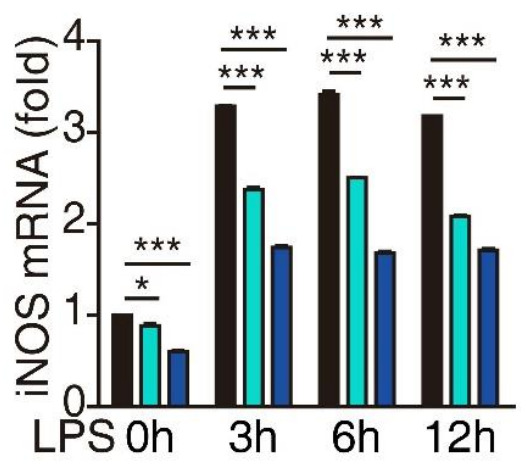

D

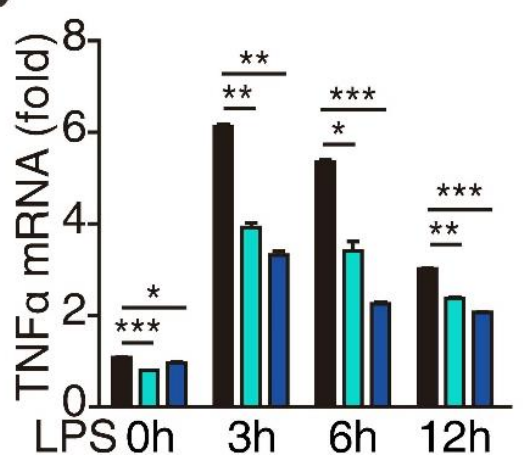

E

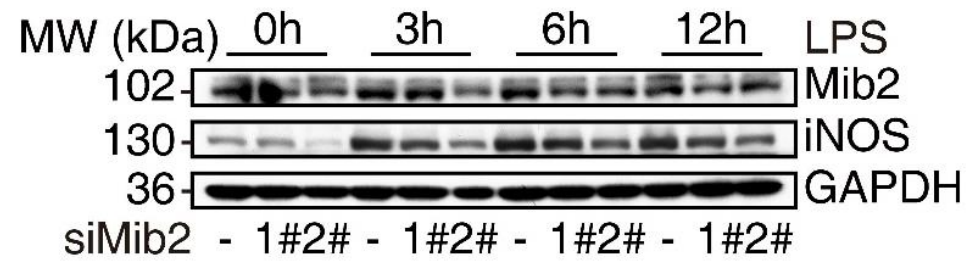

Figure 1. Mib2 knockdown inhibits LPS-induced inflammation. (A), The knockdown efficiency was determined by RT-qPCR analysis after transfected with Mib2 or control siRNA in BV2 cells for 72h. (B-D), The expression levels of IL-6, iNOS and TNF $\alpha$ in control and Mib2 knockdown-BV2 cells were analyzed upon LPS $(1 \mu \mathrm{g} / \mathrm{ml})$ stimulation for indicated times. (E), Western blot analysis of Mib2 and iNOS levels in control and Mib2 knockdown-BV2 cells upon LPS $(1 \mu \mathrm{g} / \mathrm{ml})$ stimulation for indicated times. Data indicate means \pm SEM. Data were analyzed using one-way ANOVA. $* p<0.05, * * p<0.01, * * * p<0.001$. 


\section{RESULTS}

\section{Mib2 promotes microglial activation in vitro}

To investigate whether Mib2 is involved in the microglial activation, we stimulated BV2 microglial cell line with lipopolysaccharide (LPS, $1 \mu \mathrm{g} / \mathrm{mL}$ ) for different time points. We found that the mRNA levels of Mib2 were significantly increased after LPS stimulation (Supplementary Fig. 1A), indicating that Mib2 might be involved in LPS-induced microglial activation. Previous studies showed that ischemic stroke could strongly trigger microglial activation and neuroinflammation [34, 35]. In the oxygen and glucose deprivation (OGD) model, an in vitro model of ischemia-induced damage, we observed that the mRNA levels of Mib2 were significantly upregulated after $3 \mathrm{~h}$ of OGD followed by $6 \mathrm{~h}$ of reoxygenation (Supplementary Fig. 1B). Similarly, in the animal model of transient middle cerebral artery occlusion (tMCAo), Mib2 levels were significantly increased after $3 \mathrm{~h}$ and $9 \mathrm{~h}$ of reperfusion (Supplementary Fig. 1C), suggesting that Mib2 might be involved in the early stages of stroke. Taken together, these results indicate that Mib2 is involved in the microglial activation.

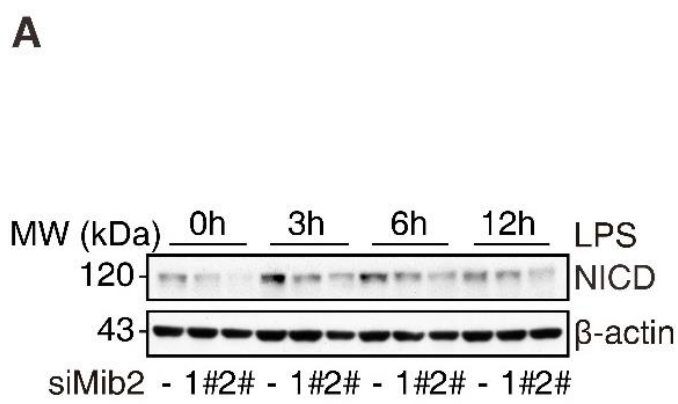

B

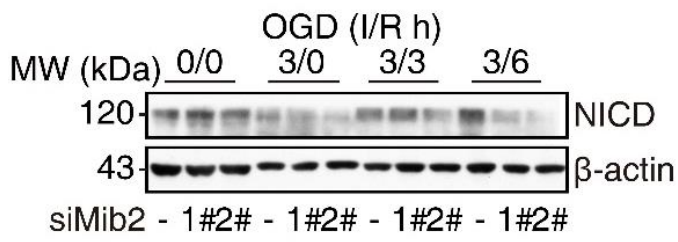

C

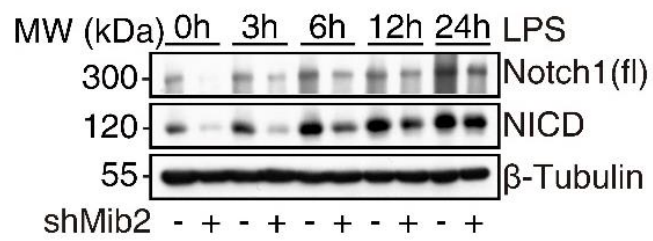

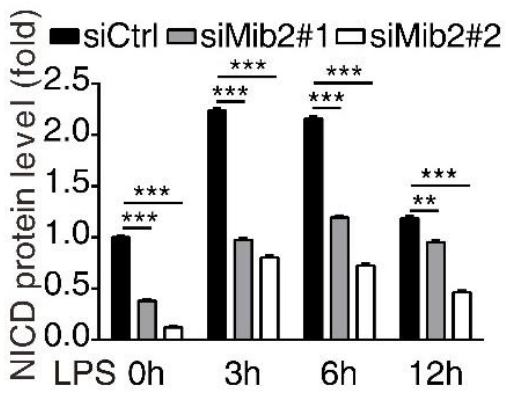

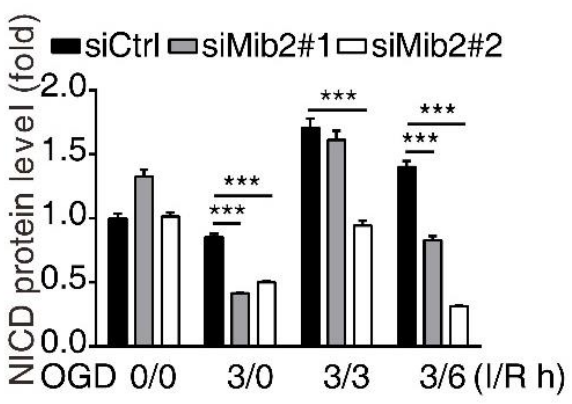

D

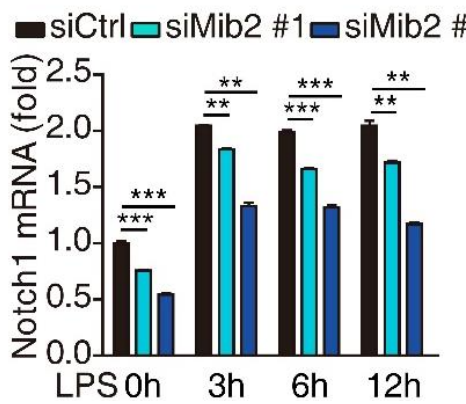

Figure 2. Mib2 regulates Notch1 signaling in microglia. (A) Western blot analysis of NICD levels (left) and relative band density quantification (right) in control and Mib2 knockdown-BV2 cells upon LPS ( $1 \mu \mathrm{g} / \mathrm{ml})$ stimulation for indicated times. (B) Western blot analysis of NICD levels (left) and relative band density quantification (right) in control and Mib2 knockdown-BV2 cells upon OGD treatment (ischemia for $3 \mathrm{~h}$ and reperfusion for indicated times), I: ischemia, R: reperfusion. (C) Western blot analysis of Notch1 (fl, full length) and NICD levels in control and Mib2 knockdown-BV2 cells upon LPS $(1 \mu \mathrm{g} / \mathrm{ml})$ stimulation for indicated times. (D) RT-qPCR analysis of Notch1 expression levels in control and Mib2 knockdown-BV2 cells upon LPS $(1 \mu \mathrm{g} / \mathrm{ml})$ stimulation for indicated times. Data indicate means \pm SEM. Data were analyzed using one-way ANOVA. $* p<0.05, * * p<0.01, * * * p<0.001$. 
To explore the role of Mib2 in microglial activation, we knocked down Mib2 in BV2 cells (Fig. 1A) and treated the cells with LPS $(1 \mu \mathrm{g} / \mathrm{mL})$ for different time points. As shown in Fig. 1B-1D, LPS stimulation significantly increased the levels of pro-inflammatory markers, including IL-6, iNOS, and TNF $\alpha$, which are reported to exacerbate brain damage during stroke [35]. Importantly, Mib2 knockdown inhibited the upregulation of these cytokines upon LPS stimulation. Further, the protein levels of iNOS were also decreased in Mib2 knockdown cells as compared to the control cells upon LPS stimulation (Fig. 1E), suggesting that Mib2 plays a critical role in microglia-mediated neuroinflammation. Similar results were obtained in the Mib2-knockdown stable BV2 cell line (Supplementary Fig. 2A-D). These data indicate that Mib2 functions as a positive regulator of microglial activation.
A

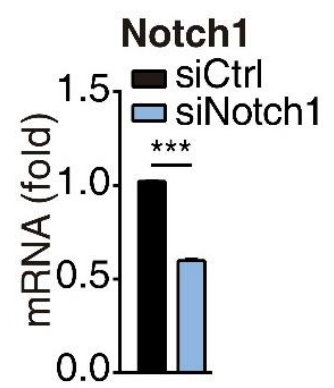

B

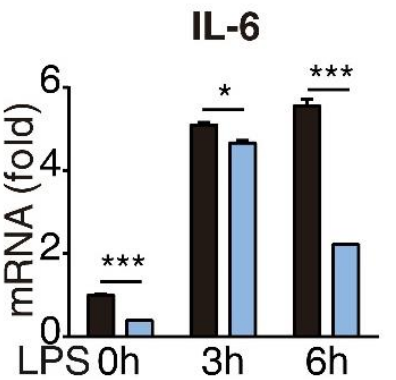

C

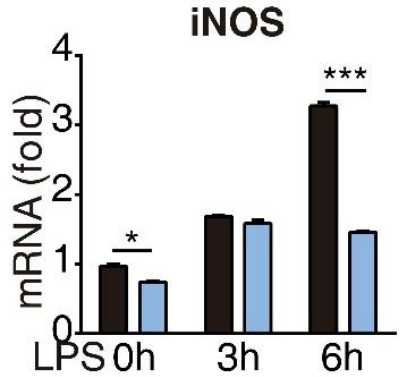

D

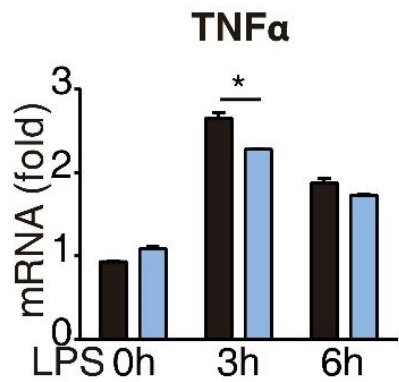

E
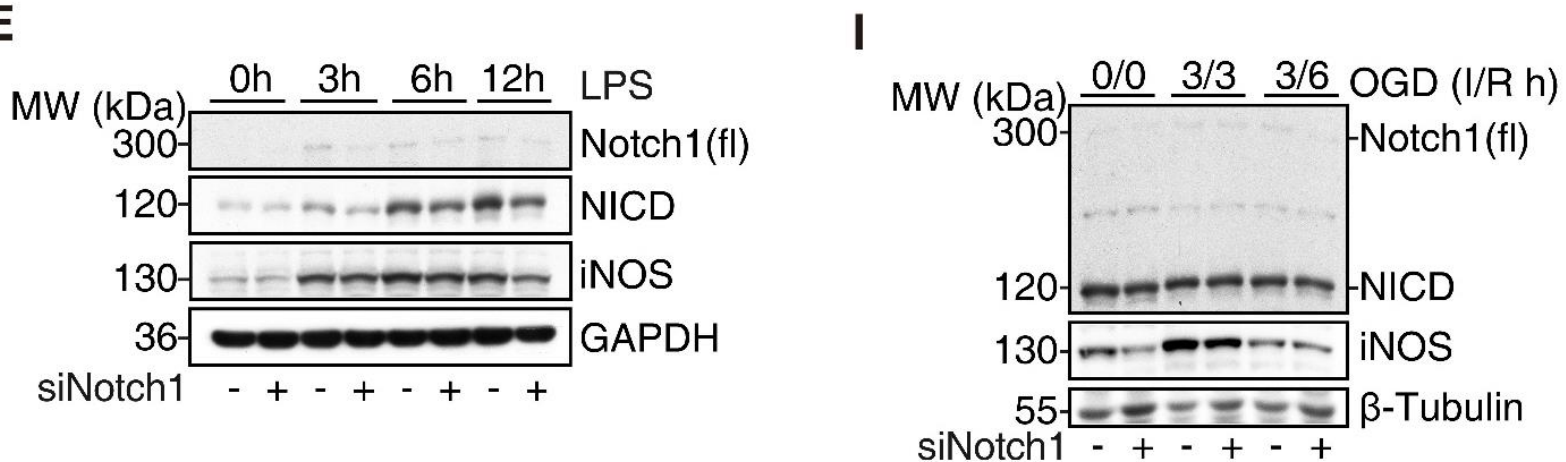
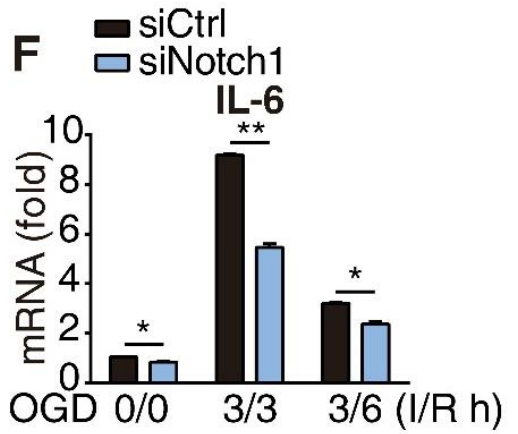

G

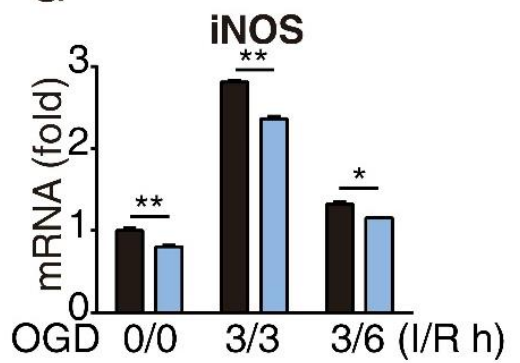

H

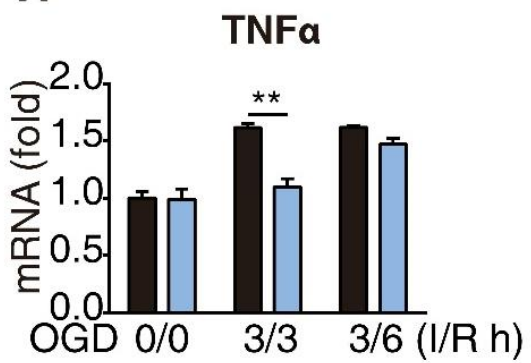

Figure 3. Notch 1 signaling regulates microglial activation. (A) The knockdown efficiency was determined by RT-qPCR analysis after transfected with Notch1 or control siRNA in BV2 cells for 72h. (B-D) The expression levels of IL-6, iNOS and TNF $\alpha$ in control and Notch1 knockdown-BV2 cells were analyzed upon LPS $(1 \mu \mathrm{g} / \mathrm{ml})$ stimulation for indicated times. (E) Western blot analysis of indicated proteins from control and Notch1 knockdown-BV2 cells upon LPS $(1 \mu \mathrm{g} / \mathrm{ml})$ stimulation for indicated times. (F-H) The expression levels of IL-6, iNOS and TNF $\alpha$ in control and Notch1 knockdown-BV2 cells were analyzed upon OGD treatment (ischemia for $3 \mathrm{~h}$ and reperfusion for indicated times), I: ischemia, R: reperfusion. (I) Western blot analysis of indicated proteins from control and Notch1 knockdown-BV2 cells upon OGD treatment (ischemia for 3h and reperfusion for indicated times), $\mathrm{I}$ : ischemia, R: reperfusion. Data indicate means \pm SEM. Data were analyzed using Student's $t$ test and one-way ANOVA. ${ }^{*} p<$ $0.05, * * p<0.01, * * * p<0.001$. 
A

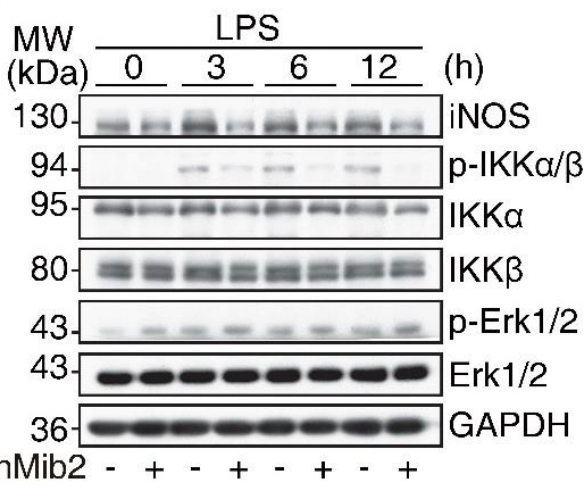

shMib2 - + - + + - +
B

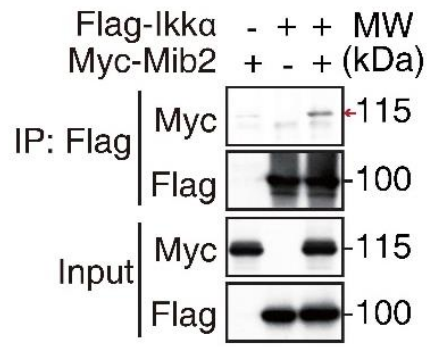

C

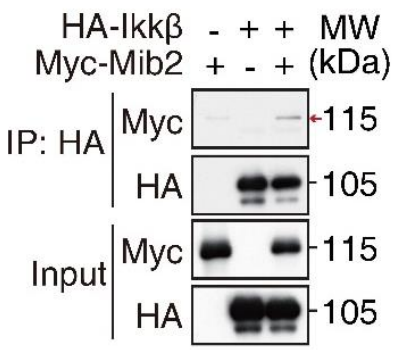

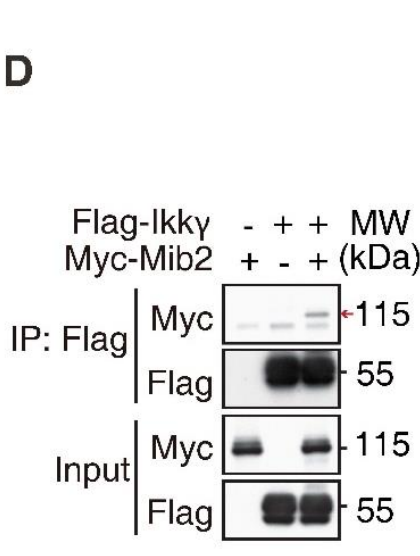

G

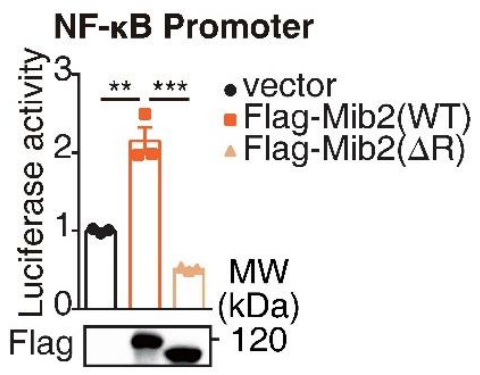

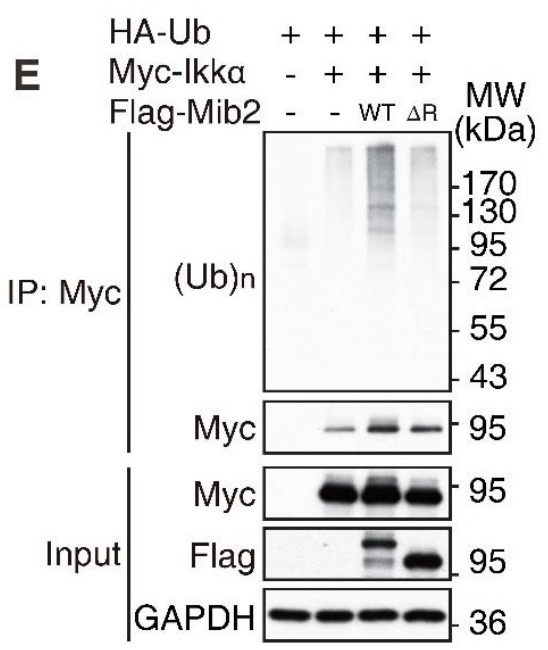

H

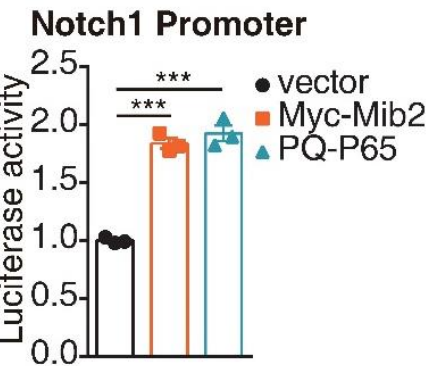

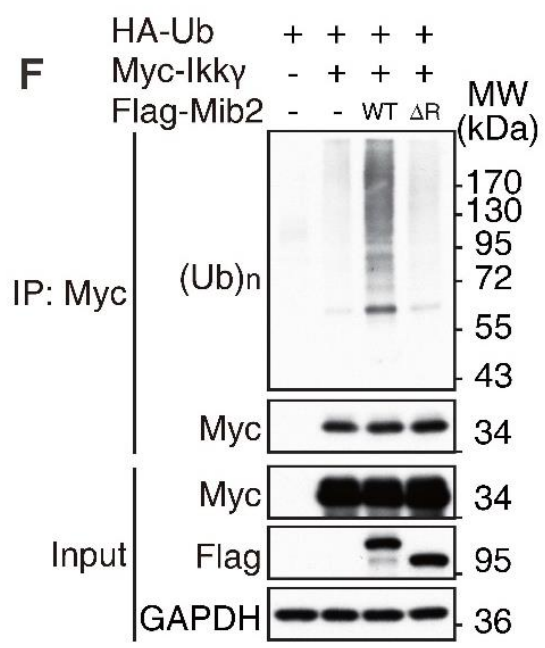

I

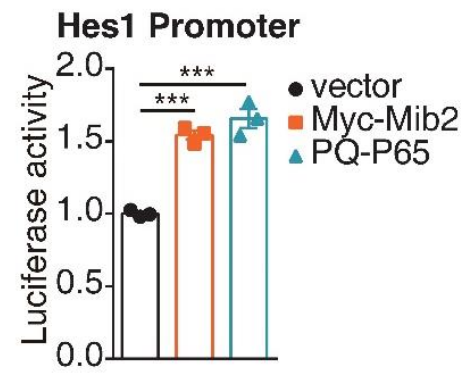

Figure 4. Mib2 regulates NF-кB signaling by targeting IKK complex. (A) Western blot analysis of iNOS and the phosphorylated and total IKK $\alpha$, IKK $\beta$, Erk, P38 levels upon LPS stimulation for indicated times in control and Mib2 knockdown BV2 cells. (B) 293T cells were transfected with Myc-tagged Mib2 and Flag-tagged IKK $\alpha$. Cell lysates were immunoprecipitation with Flag antibody and co-immunoprecipitation of Myc-tagged Mib2 was detected by Western blot analysis. (C) 293T cells were transfected with Myc-tagged Mib2 and HA-tagged IKK $\beta$. Cell lysates were immunoprecipitation with HA antibody and co-immunoprecipitation of Myc-tagged Mib2 was detected by Western blot. (D) 293T cells were transfected with Myc-tagged Mib2 and Flag-tagged IKK $\gamma$. Cell lysates were immunoprecipitation with Flag antibody and co-immunoprecipitation of Myc-tagged Mib2 was detected by Western blot analysis. (EF) $293 \mathrm{~T}$ cells were transfected with Flag-tagged Mib2 WT or $\Delta \mathrm{R}$ (Ring domain deletion) or vector plasmid together with HA-tagged ubiquitin, Myc-tagged IKK $\alpha$ or IKK $\gamma$. Cell lysates were immunoprecipitated with Myc antibody and immunoblotted with HA antibody. (G) $293 \mathrm{~T}$ cells were co-transfected with NF- $\mathrm{BB}$ luciferase reporter plasmids and Flag-Mib2 WT or $\Delta \mathrm{R}$ (Ring domain deletion) or vector plasmid, $16 \mathrm{~h}$ after transfection, cells were lysed, and the fluorescence values were measured. (H-I) 293T cells were co-transfected with Notch1 or Hes1 luciferase reporter plasmids and Myc-Mib2, P65 or vector plasmid, $16 \mathrm{~h}$ after transfection, cells were lysed, and the fluorescence values were measured. Data indicate means \pm SEM. Data were analyzed using Student's $t$ test. $* p<0.05$, **p<0.01, $* * * p<0.001$. 
A
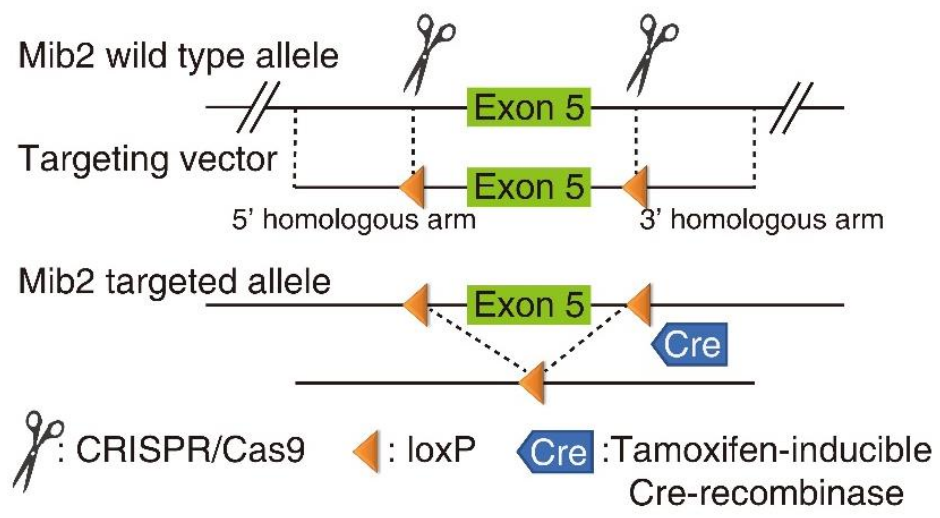

C

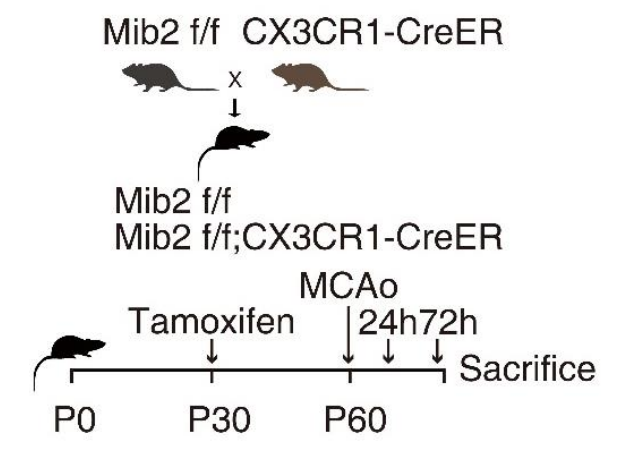

F

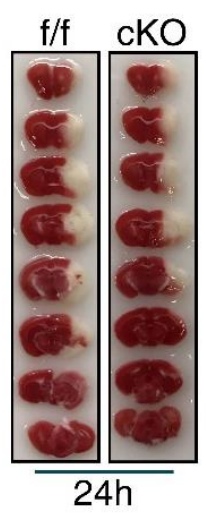

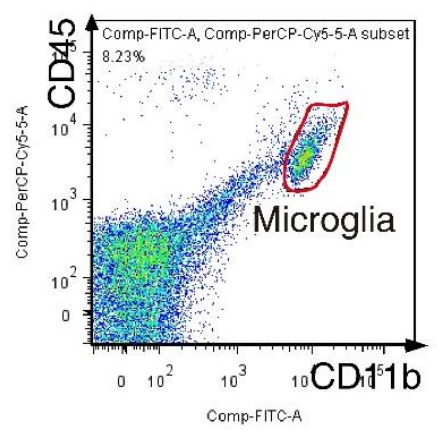

G

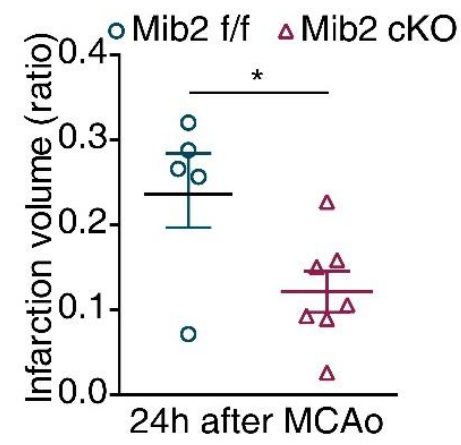

B

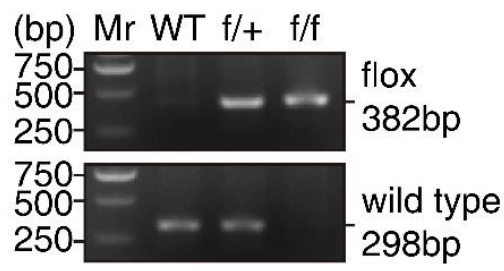

E

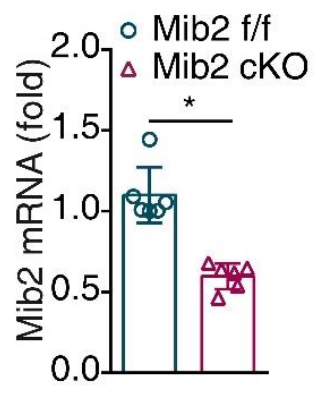

H

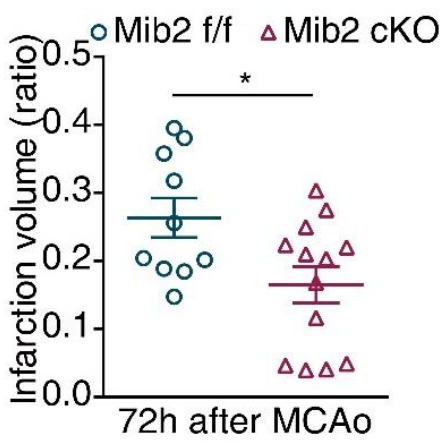

Figure 5. Microglial Mib2 knockout alleviates ischemia induced brain injury. (A) Gene strategy for Mib2 $2^{f f f}$ mice and Mib2 conditional knockout (Mib2 cKO) mice: The loxP elements were inserted upstream and downstream of exon 5 by using the CRISPR/Cas 9 method. The recombination between the loxP sites was occurred and the target sequence was deleted when Tamoxifeninducible Cre-recombinase was expressed. (B) Identification of mouse genotypes by agarose gel electrophoresis. The upper panel is for the identification of loxP site, the lower panel $s$ for the identification of wild-type allele. WT for wild-type; f/+ for Mib2 heterozygous mice; f/f for Mib2 homozygous mice. (C) Schematic of the experimental design: Mib2 ${ }^{f / f}$ mice were crossed with $\mathrm{Cx} 3 \mathrm{Cr}$ l-creER mice to obtain $\mathrm{Mib}^{\mathrm{fff}}$ and $\mathrm{Mib2} 2^{\mathrm{fff}} \mathrm{Cx} 3 \mathrm{Cr}$ l-creER littermates. These littermates were then given tamoxifen $(200 \mu \mathrm{g} / \mathrm{g}$ by intragastric administration) for three consecutive days at one-month-old to induce Mib ${ }^{f f}$ contrast and Mib2 conditional knockout (Mib2 cKO) mice. tMCAo was performed after 30-days-tamoxifen administration, mice were then sacrificed after 24 or $72 \mathrm{~h}$ reperfusion. (D) Microglia was isolated by flow cytometry from normal 2-month-old mice brain in Mib2 $2^{\text {fff }}$ and Mib2 cKO group $\left(\mathrm{CD} 11 \mathrm{~b}^{+} \mathrm{CD} 45^{\text {low }}\right.$ cells), ( $\mathrm{n}=3$ mice per group). (E) The Mib2 knockdown efficiency was determined by RT-qPCR analysis. (F) Relative images of TTC stained brain slices were shown at different time points. (G) Brain infarction volume was quantified at $24 \mathrm{~h}$ after tMCAo ( $\mathrm{n}=5$ and 7$)$. (H), Brain infarction volume was quantified at $72 \mathrm{~h}$ after tMCAo $(\mathrm{n}=10$ and 13). Data indicate means \pm SEM. Data were analyzed using Student's $t$ test. $* p<0.05, * * p<0.01$, ***p $<0.001$. 


\section{Mib2 transcriptionally regulates Notch1 signaling pathway}

Next, we asked how Mib2 regulates microglial activation. It has been reported that Mib2 regulates Notch signaling by functioning as an E3 ubiquitin ligase and promoting the endocytosis of Delta, a Notch signaling ligand [17]. Using the Ubibrowser prediction system, we found that the predicted substrates of Mib2 are mainly associated with the Notch signaling pathway [36]. Therefore, we asked whether Notch signaling is involved in Mib2mediated microglial inflammation. To address this, we knocked down Mib2 in BV2 cells. Interestingly, we found that the protein levels of the Notch1 intracellular domain (NICD), an activated form of Notch1, were significantly reduced upon Mib2 knockdown. Mib2 knockdown also markedly reduced the LPS-induced elevation of NICD (Fig. 2A), which was confirmed in the Mib2-knockdown stable BV2 cell line (Fig. 2C). Similarly, in the OGD model, we observed that Mib2 knockdown significantly reduced the re-oxygenation-induced elevation of NICD (Fig. 2B and Supplementary Fig. 3A). Since Mib2 is an E3 ubiquitin ligase that putatively recruits enzyme to its substrate proteins and targets it for degradation, we would have observed an upregulation of NICD upon Mib2 knockdown if NICD is a downstream target of Mib2. However, we found that the protein levels of NICD were reduced upon Mib2 knockdown, which failed to support that NICD is a downstream target of Mib2 ubiquitination. We then asked whether Mib2 regulates the NICD transcription. As shown in Fig. 2D, we found that Mib2 knockdown decreased the levels of Notch1 transcript and prevented the LPS-induced Notch1 upregulation, which was confirmed in the Mib2-knockdown stable BV2 cell line (Fig. 2C and Supplementary Fig. 3B). Together, these results suggest that Mib2 transcriptionally regulates Notch1 signaling in microglia.

\section{Notch1 promotes microglial activation}

Since Mib2 transcriptionally regulates the expression of Notch1/NICD in microglia, we examined the role of Notch1 signaling in microglia-mediated inflammation. We used siRNA to knockdown Notch1 in BV2 cells and treated the cells with LPS $(1 \mu \mathrm{g} / \mathrm{mL})$ for various time points. The results show that the mRNA levels of proinflammatory markers, including IL-6, iNOS, and TNF $\alpha$, were markedly reduced upon Notch1 knockdown (Fig. 3A-3D). Consistently, the protein levels of iNOS were also reduced in Notch1 knockdown cells (Fig. 3E), suggesting that Notch1 promotes microglia-mediated neuroinflammation. Notch1 knockdown also inhibited the re-oxygenation-induced microglial activation in the OGD model (Fig. 3F-3I), which is consistent with the results in
LPS-induced inflammation. Taken together, these results demonstrate that Notch1 promotes microglia-mediated inflammation. Given that Mib2 regulates the expression levels of Notch1 in the microglia, we argued that Notch1 is involved in Mib2-mediated microglial activation.

\section{Mib2 participates in microglia-mediated inflammation by targeting IKK complex of $\mathrm{NF}-\boldsymbol{\kappa} \mathrm{B}$ signaling}

In the peripheral immune system, Mib2 has been shown as an important regulator of the $\mathrm{NF}-\kappa \mathrm{B}$ signaling [18]. We hypothesized that Mib2 regulates Notch1 expression through NF- $\kappa \mathrm{B}$ signaling during LPS- and OGD-induced microglial activation. To address this, we examined the changes in the key components of NF- $\kappa \mathrm{B}$ signaling. As shown in Fig. 4A, LPS stimulation increased the protein levels of $\mathrm{p}$-IKK $\alpha$ and $\mathrm{p}$-IKK $\beta$, which were dramatically reduced upon Mib2 knockdown. Further, we found that Mib2 interacts with IKK $\alpha$, IKK $\beta$, and IKK $\gamma$ (Fig. 4B4D). Moreover, Mib2 promotes the ubiquitination levels of IKK $\alpha$ and IKK $\gamma$, while shows no effect on IKK $\beta$ (Fig. 4E, 4F and Supplementary Fig. 4). Meanwhile, Mib2 with RING domain deletion, which lacks the E3 ligase activity, failed to promote the ubiquitination, suggesting that Mib2 interacts and ubiquitinates the IKK complex in microglia.

We then evaluated the role of Mib2 in the activation of $\mathrm{NF}-\kappa \mathrm{B}$ signaling. Utilizing a dual-luciferase reporter system, we found that the expression of NF- $\kappa \mathrm{B}$ promoterluciferase was significantly increased upon overexpression of wild type Mib2, while it was remarkably reduced by the overexpression of RINGdomain deleted Mib2 (Fig. 4G), suggesting that Mib2 mediated regulation of $\mathrm{NF}-\kappa \mathrm{B}$ signaling is dependent on its E3 ubiquitin ligase activity. Accordingly, we found that the levels of both Notch1 and its downstream target, Hes1, were markedly increased upon overexpression of Mib2 and p65, an important transcription factor in the NF$\kappa \mathrm{B}$ signaling (Fig. 4H-4I), indicating that Notch1 transcription is regulated by $\mathrm{NF}-\kappa \mathrm{B}$ signaling. Together, these results suggest that Mib2 participates in microgliamediated inflammation through regulating $\mathrm{NF}-\kappa \mathrm{B}$ signaling.

\section{Microglial Mib2 knockout alleviates neurinflammation and brain injury during stroke}

To explore the function of Mib2 in vivo, we generated the inducible Mib2 microglia-specific knockout mice (Mib2 cKO mice) by crossing the Mib2 $2^{\text {flox/flox }}$ mice with the mice expressing tamoxifen (TAM)-inducible Cre-recombinase under the control of the $\mathrm{Cx} 3 \mathrm{cr} 1$ promoter $\left(\mathrm{C} \times 3 \mathrm{crl} \mathrm{C}^{\mathrm{CreER}}\right.$ mice). At postnatal day 30, mice were administered TAM and 30 days later mice were subjected to right-side tMCAo (Fig. 5A-5C). Mib2 knockout in microglia was 
confirmed by flow cytometry (Fig. 5D) and RT-qPCR (Fig. 5E). As shown in Fig. 5E, the levels of Mib2 in the cKO mice were largely reduced compared to the $M i b 2^{\text {flox } f l o x}$ mice. Further, using TTC staining, we found that the infarct volumes were significantly reduced in
Mib2 cKO mice compared with the littermates of WT mice at both, $24 \mathrm{~h}$ - and 72 h-reperfusion (Fig. 5F-5H), suggesting that microglia specific deletion of Mib2 alleviates ischemia-induced brain injury.

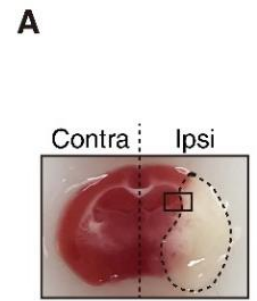

B

\section{C}

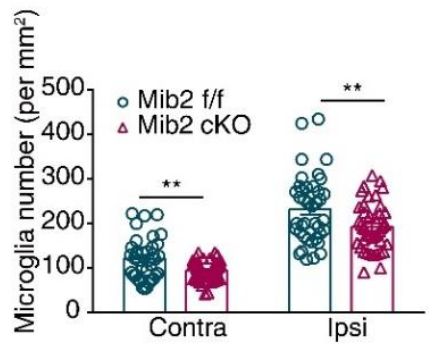

D

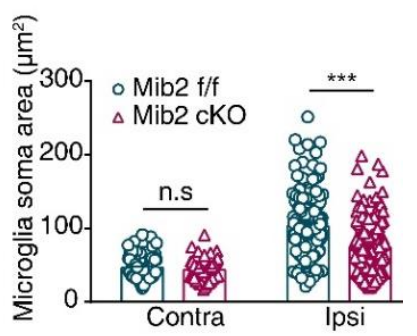

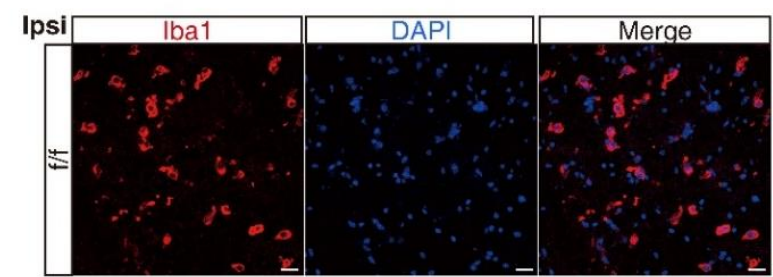
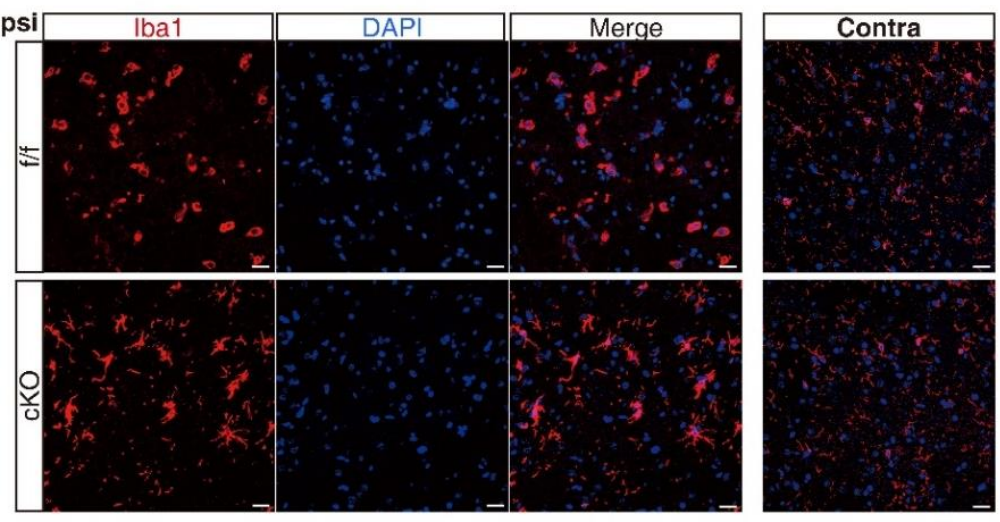

E

F

I
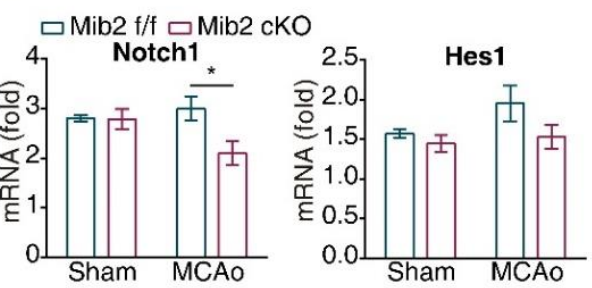

G

H
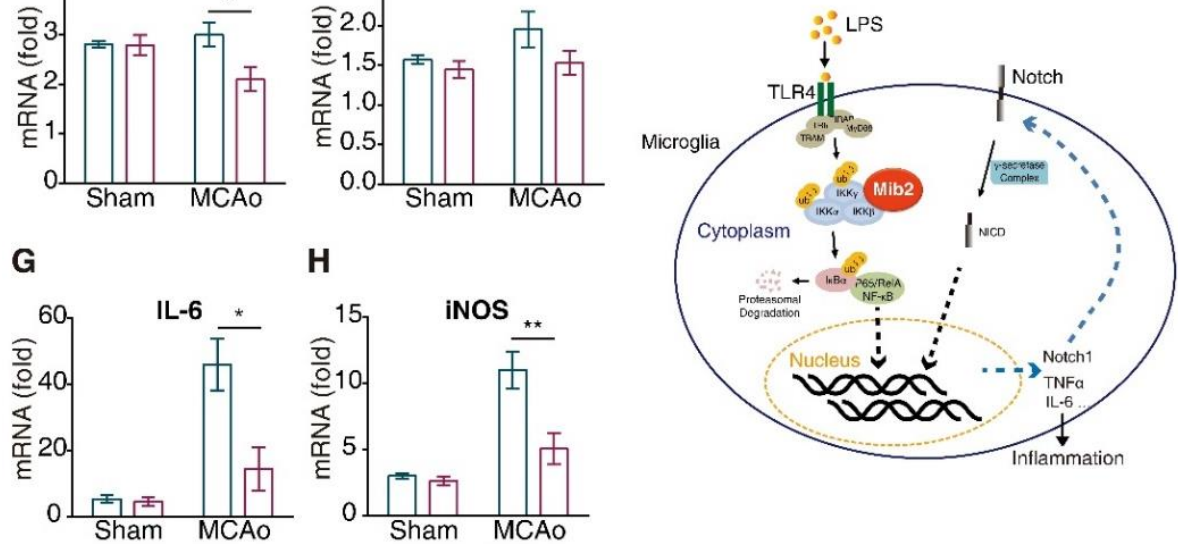

Figure 6. Microglial Mib2 knockout reduces microglial activation and inflammation. (A) The contralateral and ipsilateral of brain slices from mice underwent tMCAo and the location of ischemic penumbra. (B) Immunofluorescence staining representation of microglia in ischemic penumbra and the corresponding position on contralateral of mice underwent tMCAo after 72h reperfusion. Scale bars, $20 \mu \mathrm{m}$. (C) Quantification of microglial numbers in ischemic penumbra and the corresponding position on contralateral. (D) Quantification of microglial soma area in ischemic penumbra and the corresponding position on contralateral. (E-H), RT-qPCR analysis of Notch1, Hes1, IL-6 and iNOS expression levels in ischemic penumbra regions of brain tissues. (I) Schematic model of Mib2-regulated-inflammation in microglia. Data indicate means \pm SEM. Data were analyzed using one-way ANOVA. $* p<0.05, * * p<0.01, * * * p<0.001$. 
To study whether Mib2-mediated microglial activation is involved in this process, we performed Iba1 (a microglial marker) immunostaining and found the activated microglia in the ischemic penumbra at ipsilateral compared to corresponding contralateral position (Fig. 6A-6B). Further, the microglia in the ischemic penumbra in Mib2 cKO mice showed robust branches and small

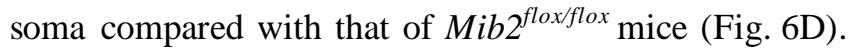
Besides, the number of microglia in Mib2 cKO mice was reduced compared to the littermates of $M i b 2^{\text {flox/flox }}$ mice (Fig. 6C). We also found that the inflammatory cytokines, including IL-6 and iNOS, were markedly decreased in the cKO mice brain (Fig. 6E-6H). Taken together, our results show that microglial deletion of Mib2 mitigates ischemiainduced neuroinflammation and stroke-induced brain injury.

In summary, we demonstrate that Mib2 interacts with the IKK complex and promotes NF- $\kappa \mathrm{B}$ signaling in the microglia. Furthermore, microglial deletion of Mib2 reduces the microglial activation, neuroinflammation, and brain damage after ischemic stroke, suggesting that Mib2 might be a potential therapeutic target in stroke treatment (Fig. 6I).

\section{DISCUSSION}

Microglial activation-induced neuroinflammation plays a critical role in many nervous system diseases including Alzheimer's disease (AD), Parkinson's disease (PD), and stroke [3-5, 37-40]. Mib2, an E3 ubiquitin ligase, has been reported to participate in regulating NF- $\kappa \mathrm{B}$ signaling and type I IFN responses in the peripheral immune system. However, its role in microglia remained unknown. Here, we found that 1) Mib2 is involved in LPS- and OGDinduced microglial activation; 2) Mib2 interacts with IKK complex proteins and transcriptionally regulates Notch signaling through NF- $\kappa \mathrm{B}$ activation; 3) Microglial specific Mib2 knockout significantly alleviates microglial activation and ischemia-induced brain injury in mice, suggesting that Mib2 might be a potential therapeutic target.

Increasing evidence showed that the NF- $\mathrm{kB}$ pathway plays a critical role in ischemia-induced brain injury [32, 41]. Inhibition of NF- $\kappa B$ signaling using pharmacological inhibitors or knocking down p50 (an NF- $\kappa \mathrm{B}$ subunit) in mice, reduced the brain injury and enhanced the functional recovery [32]. Our previous study showed that Hippo/MST signaling regulates the NF- $\kappa \mathrm{B}$ pathway and mediate microglial activation in stroke [33]. Here, we found that Mib2 promotes NF- $\mathrm{KB}$ signaling in microglia by targeting the IKK complex, thus providing additional evidence for the detrimental role of $\mathrm{NF}-\kappa \mathrm{B}$ signaling in stroke.
It has been reported that Mib2 acts as an E3 ubiquitin ligase and post-translationally regulates Notch signaling. Using a prediction system, we found that most of the Mib2 substrates are associated with the Notch pathway. However, we found that knockdown of Mib2 decreased the levels of Notch1 and its activated form NICD in the microglia. Furthermore, we found that Mib2 promotes the activation of $\mathrm{NF}-\mathrm{kB}$ signaling and transcriptionally regulates Notch expression, suggesting that Notch signaling could act as a downstream effector of the NF$\kappa \mathrm{B}$ pathway in LPS- and OGD-induced microglial activation. Also, we found that Notch signaling has a positive role in LPS- and OGD-induced microglial activation, which is consistent with previous studies [14, $42,43]$. Thus, we argue that NF- $\mathrm{kB}$ signaling could regulate Notch1 signaling and control the activation of microglia. Although we found that Mib2 interacts and ubiquitinates the IKK complex and regulates NF- $\mathrm{BB}$ signaling, the detailed regulatory mechanism needs further investigation. Future studies are required to address how Mib2 precisely regulates IKK complex.

It has been reported that Mib2 knockout mice showed impairment in hippocampal spatial memory and contextual fear memory [20], indicating that Mib2 plays an important role in the central nervous system (CNS). However, the roles of Mib2 in the CNS pathophysiology are largely unknown. Since Mib2 is upregulated in animal models of tMCAo and plays an important role in the peripheral immune system, we speculated that Mib2 might play an important role in regulating microglial activation during stroke. To study the role of Mib2 in the microglia and to exclude the effect of peripheral immune cells, we generated microglial specific conditional Mib2

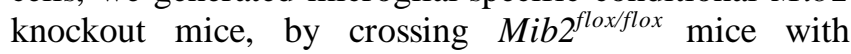
$C \times 3 \mathrm{Crl}^{\mathrm{CreER}}$ mice $[25,44]$. We are the first to report that microglial Mib2 knockout significantly alleviates ischemia-induced brain injury, suggesting that microglial Mib2 has a detrimental role in this process. Microglial activation is always accompanied by neuroinflammation, an important target for therapeutic approaches to limit stroke damage [34, 35]. Here, we found that Mib2 deficiency in microglia reduced microglial activation, including the number of microglia, the change of microglial morphology and the levels of related inflammatory cytokines.

In summary, our results suggest that Mib2 promotes microglial activation by regulating the NF- $\kappa \mathrm{B}$ pathway. Microglial Mib2 knockout protects ischemia-induced brain injury, suggesting that Mib2 might be a potential therapeutic target in stroke treatment. 


\section{Acknowledgments}

We appreciate Prof. Fengchao Wang in National Institute of Biological Sciences for Mib2 conditional knockout mice. This work was supported by the National Nature Science Foundation of China (Grant Nos 81870839, 81630026 and 81701187), the National Major Project of Support Program (Grant No AWS17J013), the Beijing Nature Science Foundation (Grant No 7161009) and Chinese Postdoctoral Science Foundation (Grant No 2017M613411).

\section{Competing financial interests}

The authors declare no competing financial interests.

\section{Supplementary Materials}

The Supplemenantry data can be found online at: www.aginganddisease.org/EN/10.14336/AD.2019.0807.

\section{References}

[1] Gendelman HE (2002). Neural immunity: Friend or foe? J Neurovirol, 8:474-479.

[2] Aguzzi A, Barres BA, Bennett ML (2013). Microglia: scapegoat, saboteur, or something else? Science, 339:156-161.

[3] Xanthos DN, Sandkuhler J (2014). Neurogenic neuroinflammation: inflammatory CNS reactions in response to neuronal activity. Nat Rev Neurosci, 15:4353.

[4] Iadecola C, Anrather J (2011). The immunology of stroke: from mechanisms to translation. Nat Med, 17:796-808.

[5] Macrez R, Ali C, Toutirais O, Le Mauff B, Defer G, Dirnagl U, et al. (2011). Stroke and the immune system: from pathophysiology to new therapeutic strategies. Lancet Neurol, 10:471-480.

[6] Benakis C, Garcia-Bonilla L, Iadecola C, Anrather J (2014). The role of microglia and myeloid immune cells in acute cerebral ischemia. Front Cell Neurosci, 8:461.

[7] Salter MW, Stevens B (2017). Microglia emerge as central players in brain disease. Nat Med, 23:1018-1027.

[8] Graeber MB (2010). Changing face of microglia. Science, 330:783-788.

[9] Hu X, Leak RK, Shi Y, Suenaga J, Gao Y, Zheng P, et al. (2015). Microglial and macrophage polarization-new prospects for brain repair. Nat Rev Neurol, 11:56-64.

[10] Li D, Lang W, Zhou C, Wu C, Zhang F, Liu Q, et al. (2018). Upregulation of Microglial ZEB1 Ameliorates Brain Damage after Acute Ischemic Stroke. Cell Rep, 22:3574-3586.

[11] Ma Y, Wang J, Wang Y, Yang GY (2017). The biphasic function of microglia in ischemic stroke. Prog Neurobiol, 157:247-272.

[12] Anttila JE, Whitaker KW, Wires ES, Harvey BK, Airavaara M (2017). Role of microgliain ischemic focal stroke and recovery: focus on Toll-like receptors. Prog NeuropsychopharmacolBiol Psychiatry, 79:3-14.

[13] Shichita T, Hasegawa E, Kimura A, Morita R, Sakaguchi $\mathrm{R}$, Takada I, et al. (2012). Peroxiredoxin family proteins are key initiators of post-ischemic inflammation in the brain. Nat Med, 18:911-917.

[14] Wei Z, Chigurupati S, Arumugam TV, Jo DG, Li H, Chan SL (2011). Notch activation enhances the microgliamediated inflammatory response associated with focal cerebral ischemia. Stroke, 42:2589-2594.

[15] Caldeira MV, Salazar IL, Curcio M, Canzoniero LM, Duarte CB (2014). Role of the ubiquitin-proteasome system in brain ischemia: friend or foe? Prog Neurobiol, 112:50-69.

[16] Itoh M, Kim CH, Palardy G, Oda T, Jiang YJ, Maust D, et al. (2003). Mind bomb is a ubiquitin ligase that is essential for efficient activation of Notch signaling by Delta. Dev Cell, 4:67-82.

[17] Koo BK, Yoon KJ, Yoo KW, Lim HS, Song R, So JH, et al. (2005). Mind bomb-2 is an E3 ligase for Notch ligand. J Biol Chem, 280:22335-22342.

[18] Stempin CC, Chi L, Giraldo-Vela JP, High AA, Hacker $\mathrm{H}$, Redecke V (2011). The E3 ubiquitin ligase mind bomb-2 (MIB2) protein controls B-cell CLL/lymphoma 10 (BCL10)-dependent NF-kappaB activation. J Biol Chem, 286:37147-37157.

[19] Kumagai Y, Akira S (2011). Mind bomb proteins in the antiviral arsenal. Immunity, 35:320-322.

[20] Kim S, Kim T, Lee HR, Kong YY, Kaang BK (2015). Mind Bomb-2 Regulates Hippocampus-dependent Memory Formation and Synaptic Plasticity. Korean J Physiol Pharmacol, 19:515-522.

[21] Jurd R, Thornton C, Wang J, Luong K, Phamluong K, Kharazia V, et al. (2008). Mind bomb-2 is an E3 ligase that ubiquitinates the N-methyl-D-aspartate receptor NR2B subunit in a phosphorylation-dependent manner. J Biol Chem, 283:301-310.

[22] Zemoura K, Trumpler C, BenkeD (2016). Lys-63-linked Ubiquitination of gamma-Aminobutyric Acid (GABA), Type B1, at Multiple Sites by the E3 Ligase Mind Bomb2 Targets GABAB Receptors to Lysosomal Degradation. J Biol Chem, 291:21682-21693.

[23] Zemoura K, Balakrishnan K, Grampp T, BenkeD (2018). $\mathrm{Ca}(2+) /$ Calmodulin-Dependent Protein Kinase II (CaMKII) beta-Dependent Phosphorylation of GABAB1 Triggers Lysosomal Degradation of GABAB Receptors via Mind Bomb-2 (MIB2)-Mediated Lys-63-Linked Ubiquitination. Mol Neurobiol.

[24] Zhang Y, Chen K, Sloan SA, Bennett ML, Scholze AR, O'Keeffe S, et al. (2014). An RNA-sequencing transcriptome and splicing database of glia, neurons, and vascular cells of the cerebral cortex. J Neurosci, 34:11929-11947.

[25] Yona S, Kim KW, WolfY, Mildner A, VarolD, Breker M, et al. (2013). Fate mapping reveals origins and dynamics of monocytes and tissue macrophages under homeostasis. Immunity, 38:79-91.

[26] Wu R, Chen H, Ma J, He Q, Huang Q, Liu Q, et al. (2016). c-Abl-p38alpha signaling plays an important role in MPTP-induced neuronal death. Cell Death Differ, 
$23: 542-552$.

[27] Zhou L, Zhang Q, Zhang P, Sun L, Peng C, YuanZ, et al. (2017).c-Abl-mediated Drp 1 phosphorylation promotes oxidative stress-induced mitochondrial fragmentation and neuronal cell death. CellDeath Dis, 8:e3117.

[28] Wu R, Liu XM, Sun JG, Chen H, Ma J, Dong M, et al. (2017). DJ-1 maintains energy and glucose homeostasis by regulating the function of brown adipose tissue. Cell Discov, 3:16054.

[29] Ford AL, Goodsall AL, Hickey WF, Sedgwick JD (1995). Normal adult ramified microglia separated from other central nervous system macrophages by flow cytometric sorting. Phenotypic differences defined and direct ex vivo antigen presentation to myelin basic proteinreactive CD4+ T cells compared. J Immunol, 154:43094321.

[30] Sedgwick JD, Schwender S, Imrich H, Dorries R, Butcher GW, ter Meulen V (1991). Isolation and direct characterization of resident microglial cells from the normal and inflamed central nervous system. Proc Natl Acad Sci U S A, 88:7438-7442.

[31] Wu LJ, Wu G, Akhavan Sharif MR, Baker A, Jia Y, Fahey FH, et al. (2012). The voltage-gated proton channel Hv1 enhances brain damage from ischemic stroke. Nat Neurosci, 15:565-573.

[32] Venna VR, Weston G, Benashski SE, Tarabishy S, Liu F, Li J, et al. (2012). NF-kappaB contributes to the detrimental effects of social isolation after experimental stroke. Acta Neuropathol, 124:425-438.

[33] Zhao S, Yin J, Zhou L, Yan F, He Q, Huang L, et al. (2016). Hippo/MST1 signaling mediates microglial activation following acute cerebral ischemia-reperfusion injury. Brain Behav Immun, 55:236-248.

[34] Wood PL(1995). Microglia as a unique cellular target in the treatment of stroke: potential neurotoxic mediators produced by activated microglia. Neurol Res, 17:242248.
[35] Patel AR, Ritzel R, McCullough LD, Liu F (2013). Microglia and ischemic stroke: a double-edged sword. Int J Physiol Pathophysiol Pharmacol, 5:73-90.

[36] Li Y, Xie P, Lu L, Wang J, Diao L, Liu Z, et al. (2017). An integrated bioinformatics platform for investigating the human E3 ubiquitin ligase-substrate interaction network. Nat Commun, 8:347.

[37] Heneka MT, Golenbock DT, Latz E (2015). Innate immunity in Alzheimer's disease. Nat Immunol, 16:229. 236.

[38] Heppner FL, RansohoffRM, Becher B (2015). Immune attack: the role of inflammation in Alzheimer disease. Nat Rev Neurosci, 16:358-372.

[39] Stone DK, Reynolds AD, Mosley RL, Gendelman HE (2009). Innate and adaptive immunity for the pathobiology of Parkinson's disease. Antioxid Redox Signal, 11:2151-2166.

[40] Cheng J, Liao Y, Xiao L, Wu R, Zhao S, Chen H, et al. (2017). Autophagy regulates MAVS signaling activation in a phosphorylation-dependent manner in microglia. Cell Death Differ, 24:276-287.

[41] Arumugam TV, Baik SH, Balaganapathy P, Sobey CG, Mattson MP, Jo DG (2018). Notch signaling and neuronal death in stroke. Prog Neurobiol, 165-167:103116.

[42] Tsao PN, Wei SC, Huang MT, Lee MC, Chou HC, Chen CY, et al. (2011). Lipopolysaccharide-induced Notch signaling activation through JNK-dependent pathway regulates inflammatory response. J Biomed Sci, 18:56.

[43] Arumugam TV, Chan SL, Jo DG, Yilmaz G, Tang SC, Cheng A, et al. (2006). Gamma secretase-mediated Notch signaling worsens brain damage and functional outcome in ischemic stroke. Nat Med, 12:621-623.

[44] Parkhurst CN, Yang G, Ninan I, Savas JN, Yates JR, 3rd, Lafaille JJ, et al. (2013). Microglia promote learningdependent synapse formation through brain-derived neurotrophic factor. Cell, 155:1596-1609. 